\title{
Wastewater discharge impact on an important river of the Lerma-Chapala watershed, Mexico
}

\author{
C. Fall, A. P. Hinojosa, M. C. M. Jiménez \& M. C. L Carreño \\ Autonomous University of the State of Mexico (CIRA-UAEM), Mexico
}

\begin{abstract}
The Lerma-Chapala watershed is one of the most important hydrological systems of Mexico. The Lerma, the main river of the catchment was subjected to receive increased volumes of untreated wastewaters. The research initiated consisted of producing an inventory and classifying the discharge sites, designing a strategic monitoring network and a computerized database, as well as evaluating the quality of the river water and wastewater received. The results showed 51 discharges throughout the high course of the river (the first $60 \mathrm{~km}$ ). Discharge sites were localized with a GPS and included on a map and database. A monitoring network of 21 sampling stations was proposed, from which 15 stations were selected to evaluate the water quality of the river, together with other 13 priority discharge sources. The average concentrations measured at the 15 sampling stations of the Lerma, during the wet season, were $<0.5 \mathrm{mg} / \mathrm{L} \mathrm{O}{ }_{2}$ (at most of the sampling point), $149 \mathrm{mg} / \mathrm{L}$ COD and $492 \mathrm{mg} / \mathrm{L}$ of total solids, against $0.4 \mathrm{mg} / \mathrm{L}$ of $\mathrm{O}_{2}, 388 \mathrm{mg} / \mathrm{L} \mathrm{COD}$ and $2752 \mathrm{mg} / \mathrm{L} \mathrm{TTS}$ in the dry season. The same septic conditions were observed in many of the discharges. Microtox based toxicity analyses showed that 7 of the 13 evaluated discharges, during the dry whether, compared with 2 during the wet season, were extremely toxic to the Microtox test organism ( $\mathrm{TU}>5$ ). With respect to the river, 13 of the 15 samples were analyzed in the dry season against 1 of 15 in the wet season, showing very toxic characteristics. The results obtained evidenced the actual state of the river during the dry season, a significant wastewater collector, showing the urgency to implement a sanitation program in the basin and initiate remediation of the watercourse.
\end{abstract}

Keywords: Lerma River, microtox, discharges, monitoring stations, physicochemical characteristics. 


\section{Introduction}

The hydrologic system Lerma-Chapala constitutes one of the most important watersheds in Mexico. It is formed by the Lerma River, Chapala Lake and Santiago River. The region is drained by the rivers Lerma and Santiago as main collectors. Together they are $1180 \mathrm{~km}$ long, from which $60 \%$ correspond to Lerma and $40 \%$ to Santiago River. The High Watershed of Lerma River is located in the State of Mexico, subdivided in three portions called High, Medium and Low Courses, with a total length of $175 \mathrm{~km}$. The High Course $(60 \mathrm{~km}$.) corresponds to the region that is located between the source lagoon and a point about 9 kilometers after the Alzate dam (CCRECRL [1]).

In the past, the Lerma River ecosystem included different kinds of fish, crustaceous and marine bird species, of which what is left today, is only a memory. Demographic growth and concomitant industrialization have generated serious pollution problems in the Lerma River (De la Fuente et al. [2]).

In the last years, a larger number of environmental studies were started on Lerma River (Avila-Pérez et al. [3], Barceló et al. [4], Mantilla-Morales et al. [5]), in order to better know the conditions and suggest potential solutions. The last studies were interested not only in the conventional parameters (BOD, DO, Solids, etc.) but also metals, persisting organic compounds, the sediments' quality, aquatic plants, toxicity and health aspects of the riverain population. Even if there is more information about the river, the combined integration and interpretation of these data will not be possible without a common data base, or that the sampling stations used for each actor are not referenced or traceable. For this, the objective of this research was: $1^{\text {st }}$ ) to design a permanent strategic network of monitoring stations for the High Course of Lerma River (HCLR); $2^{\text {nd }}$ ) to use the stations of this network to evaluate the spatial and temporal variability of the course water quality and the impact of the discharges it receives.

\section{Methods}

\subsection{Design of the monitoring network}

The zone of interest formed by the High Course of Lerma River (HCLR) goes from the Chiconahuapan lagoon in Almoloya del Río, to $9 \mathrm{~km}$ down the exit of the Juan Alzate dam. A complete on-foot travel of the zone was taken in order to: make an inventory and position in detail with a GPS the different discharges of wastewaters, including the main tributaries. As a result, a detail map of the discharges was obtained, which was fundamental to the designing of the network.

The monitoring network was integrated by stations in the heart of the river (type R) and stations located in the different discharges (type D). The type D stations were selected under the hypothesis that the larger discharges would be determinant to the rivers' water quality. On the other hand, the main criteria to set the stations location (type R) in the river were that the sampling sites would 
be accessible, to be distributed along the HCLR, that there were a point before and after each important discharge, and whenever possible, to preserve most of the old stations used before by universities and water Agencies. The characterization performed in this work was based on a limited number of discharge stations (type R) and river stations (type R), selected within the sites that comprehend the general monitoring network.

\subsection{Characterization of the river waters and of the discharges it receives}

The discharges to be monitored were selected among those that contribute with more flow to the river, including polluted or non-polluted tributaries (small rivers) that join in. All the stations in the river were two hundred meters or more from the large discharges, in places where the contaminant plumes have visibly finished mixing. The discharge sampling stations were within the $30 \mathrm{~m}$ preceding their junction to the Lerma River.

Two sampling campaigns were performed in the selected locations for the monitoring, the first one in the wet season (September) and the other in dry season (March). Simple samples were taken in the center of the current, at a third of the depth. At the same time, the currents' velocity and parameters such as conductivity (Cond.), temperature (Temp.) and dissolved oxygen (D.O.) were measured in situ (portable equipments WTW P4 and YSI 57). The different samples were refrigerated at $4^{\circ} \mathrm{C}$ with the adequate preservatives and were later analyzed to determine $\mathrm{pH}$, turbidity (Turb), chemical oxygen demand (COD hatch kit), solids in all their forms (TTS: totals; TDS and VDS: total dissolved and volatile; TSS and VSS: total suspended and volatile), according to the standard methods (APHA [6]). An aliquot of $50 \mathrm{~mL}$, without a preservative, separated since the sampling in glass bottles (free of air), was analyzed by the Microtox $^{\mathrm{TM}}$ system (Azur Environmental Inc., California, USA) to trace the presence of toxic compounds (acute toxicity test). The obtained measurement was the effective concentration at 50\% (EC50), later converted to toxicity units (TU $=100 /$ EC50). The samples showing hormesis or an EC50 higher than $100 \%$ $(\mathrm{TU}<1)$ were considered non-toxic.

\section{Results and discussions}

\subsection{Proposal of the monitoring network and its application to this work}

In the work were registered 51 discharges, which included 21 canals $(41 \%$ of the discharges), 19 tubes (37\%), 4 brooks (8\%) and 7 small rivers (R, 14\%) that flow into the Lerma, and that generally have untreated wastewaters from the communities of the region. The set of information regarding the inventory was presented in an atlas with a more detailed individual description of each discharge or tributary of interest (Hinojosa-Peña [7]).

Most of the discharges come from different municipalities to evacuate the domestic and industrial wastewaters. Moreover, three important treatment plants in the Toluca municipality (2 municipal and 1 industrial) discharge their 
effluents (approx. $2.5 \mathrm{~m}^{3} / \mathrm{s}$ ) in the Lerma High Course. Also 7 small rivers, located all of them in the second half of the Course, do the same. The diameters or width of the more visible tubes, canals and tributaries vary from $0.3 \mathrm{~m}$ to $15 \mathrm{~m}$, with an average of $2.8 \mathrm{~m}$, a median of 0.75 and a mode of $0.5 \mathrm{~m} .40 \%$ of the discharges have a dimension smaller or equal to $0.5 \mathrm{~m}$ whereas those of 0.5 to $2 \mathrm{~m}$ are $25 \%$, those from 2 to $5 \mathrm{~m}, 20 \%$ and those from 5 to $15 \mathrm{~m}, 15 \%$. The small discharges $(<0.5 \mathrm{~m})$ usually come from very close zones to the river, whereas the tubes, canals and tributaries are collectors of several kilometres. It was inferred that the total contribution, in caudal and contaminant load, of the relatively large sized discharges $(>2 \mathrm{~m})$ could be determinant on the quality of the river.

With the design of monitoring network in the river and its discharges, it was expected to have continuity and traceability of the data generated throughout the time by different actors. This will make possible to regroup the information in a coherent way in a database and propitiate future opportunities of performing studies of temporal and spatial variation over the different parameters. Software (Info-Lerma) was created to build a database of all the information that is or would be available about the quality of the water and river's sediments (Ramírez and Hernández [8]).

Based on the discharges data, it was proposed a sampling network of 21 stations in the river (R1 to R20) and 13 in the important discharges (D1 to D13), all geo-positioned with a GPS so that every researcher could be able to select among them the ones that would be more relevant to their study in particular, without losing the traceability. The type $\mathrm{D}$ stations were all located in discharges of $2 \mathrm{~m}$ or larger, selecting within this class, the most representative.

For the application of the monitoring network, in this work, the 13 discharge stations (D) were selected, but not all the 21 type $\mathrm{R}$ sites were used (only 15 of them). Figure 1 is a partial view of the monitoring network.

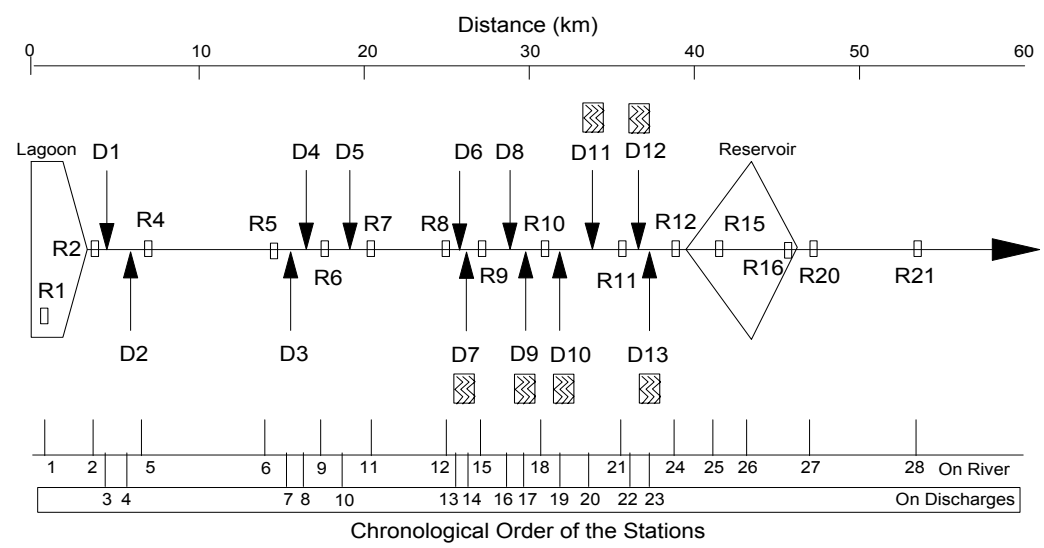

Figure 1: Monitoring network of the Lerma River. 
In this figure, the stations that were selected for this specific case are shown, visualizing also the relative position of the discharges with respect to the stations inside the river. In this graphic, the tributaries marked with a flag correspond to small rivers that feed the Lerma (Xonacatlán, S. Catarina, San Lorenzo, Temoaya, Verdiguel and Tejalpa). In the lower part of the figure, the sequential order of all the sampling stations (type R and D together) is given, for its use in later graphics as reference.

The first two stations of the network (R1 and R2) are located in the lagoon which was in the past the origin of the river and that nowadays is isolated with a soil barrier to avoid that, in summer times, the direction of flow inverts and part of the discharges reach the lagoon. Just after the lagoon, at the beginning of the river course, are R3 (not used in this work) and R4, which allow one to evaluate the water quality before and after the first important discharges, the Tenango Drainage and the Mezapa Stream (D1 and D2), which are part of the discharges monitoring network. The rest of the first half of the HCLR is covered by stations R5, R6 and R7, focused on detecting the impact of the municipal drainages of Chapultepec, San Lucas Tunca and Ocoyoacac (D3), Metepec and San Mateo (D4), as well as the discharge from a wastewater treating plant of an industrial park (D5). The R8 to R12 stations are placed between the 7 small rivers. In this zone, six out of the 7 small tributaries, as well as two canals that conduct the effluents of the two macro-plants of Toluca constitute the rest of the monitoring network for the discharges (D6 to D13). The treated effluents may mix, down the canals, with other non-treated flows. The Alzate reservoir, located in the last length of the HCLR, due to its large surface, accommodates 6 R-stations (R13 to R18). The sampling sites intensively used by several researchers who concentrated their works on the Alzate reservoir were conserved. From those, only two (R15 and R16) were included in the monitoring performed in this work. The last stations of the R-network (R20 and R21) were located between the dam curtain and the HCLR limit (9 km down the curtain), in order to detect the changes suffered at the exit of the reservoir and follow their behavior along two more locations. There was not installed any D-sampling station in the last length since there is not any important discharge in that zone.

\subsection{Characteristics of the river waters}

Table 1 and Figure 2 show the spatial and temporal variation of the water characteristics in the river and in the discharges. In general, for all the represented parameters, there is significant change between the order of magnitude in dry season compared to the wet season, for the discharges as well for the river water column. The only evident exceptions were the $\mathrm{pH}$ and the dissolved oxygen (Figure 2B), which vary almost in the same ranges between a period and the next.

By focusing on the spatial variability of the $\mathrm{R}$ stations parameters (inside the course), it is observed that the quality of the water column is deteriorated since the beginning, in all the seasons, as the dissolve oxygen profiles notably evidence (Figure 2A). The D.O. that reaches relatively high values in the first part of the lagoon $(5$ and $8 \mathrm{mg} / \mathrm{L})$, all of the sudden relapses to levels between 0 
and $1 \mathrm{mg} / \mathrm{L}$ before exiting the lagoon, as well as after leaving it. At the end, but only temporally, it was observed that the water is re-oxygenated due to the fall of the liquid from the Alzate dam floodgate (point numbered as 27). In any of the periods, the COD reaches values higher than $150 \mathrm{mg} / \mathrm{L}$ from the first sampling stations, inside as well as outside the lagoon (Figure 2B). Throughout the 30 COD measurements performed during the two periods, only 4 presented values lower that $100 \mathrm{mg} / \mathrm{L}(90,83,56$ and $64 \mathrm{mg} / \mathrm{L}$ in wet season, respectively for the numbers of order 5, 21, 25 and 26, or stations R5, R11, R15 and R16). In the sampling in dry season, the COD fluctuated from 190 to $1200 \mathrm{mg} / \mathrm{L}$ depending on the station. Also for the dry season (only), conductivity and total dissolved solids (Figure 2C), as well as toxicity (Figure 2D) show relatively high values: on average, conductivity of 1300 in dry season against $700 \mu \mathrm{S} / \mathrm{cm}$ in wet season, $14 \mathrm{TU}(\mathrm{EC} 50=7 \%)$ in dry season against less than $1 \mathrm{TU}(\mathrm{EC} 50>100 \%)$ in general, during the wet season.

The averages for turbidity and total suspended solids (TSS) in the river were about $170 \mathrm{NTU}$ and $164 \mathrm{mg} / \mathrm{L}$ TSS against $61 \mathrm{NTU}$ and $112 \mathrm{mg} / \mathrm{L} \mathrm{TSS}$, in low and high waters, respectively. The maximum values were manifested in low waters with $600 \mathrm{NTU}$ of turbidity and $770 \mathrm{mg} / \mathrm{l} \mathrm{TSS}$.

Table 1: $\quad$ Statistics of the river and discharges characteristics.

\begin{tabular}{|c|c|c|c|c|c|c|c|c|}
\hline \multirow{3}{*}{ Parameters } & \multicolumn{4}{|c|}{ River } & \multicolumn{4}{|c|}{ Discharges } \\
\hline & \multicolumn{2}{|c|}{ Dry season } & \multicolumn{2}{|c|}{ Wet season } & \multicolumn{2}{|c|}{ Dry season } & \multicolumn{2}{|c|}{ Wet season } \\
\hline & Mean & Range & Mean & Range & Mean & Range & Mean & Range \\
\hline pH (units) & 7.5 & $7.0-8.5$ & 6.9 & $6.4-7.2$ & 7.2 & $5.5-7.6$ & 7.1 & $6.0-8.6$ \\
\hline Cond $(\mu \mathrm{S} / \mathrm{cm})$ & 1344 & $936-2040$ & 684 & $461-1532$ & 1079 & $144-4860$ & 698 & $108-3000$ \\
\hline Turb. (NTU) & 161 & $49-598$ & 61 & $7-207$ & 136 & $44-307$ & 68 & $17-209$ \\
\hline D.O. (mg/L) & 1.2 & $0-8.0$ & 1.3 & $0-5.0$ & 2.1 & $0-8.0$ & 1.6 & $0-6.4$ \\
\hline $\mathrm{COD}(\mathrm{mg} / \mathrm{L})$ & 388 & $188-1206$ & 149 & $56-209$ & 364 & $21-1312$ & 112 & $36-224$ \\
\hline $\mathrm{TSS}(\mathrm{mg} / \mathrm{L})$ & 164 & $66-770$ & 92 & $17-235$ & 124 & $30-316$ & 115 & $36-220$ \\
\hline TDS (mg/L) & 2348 & $\begin{array}{l}1686- \\
4490\end{array}$ & 401 & $275-600$ & 2106 & $\begin{array}{l}1759- \\
3372\end{array}$ & 460 & $90-1368$ \\
\hline VSS (\% of TSS) & $71 \%$ & $52-89 \%$ & $43 \%$ & $18-88 \%$ & $74 \%$ & $44-92 \%$ & $40 \%$ & $15-74 \%$ \\
\hline VDS (\% of TDS) & $31 \%$ & $22-41 \%$ & $25 \%$ & $11-40 \%$ & $31 \%$ & $22-39 \%$ & $25 \%$ & $13-51 \%$ \\
\hline Toxicity (TU) ${ }^{\#}$ & 14.3 & $<1-151^{+}$ & 1.9 & $<1-15$ & 5.1 & $<1-29$ & 1.5 & $<1-170^{+}$ \\
\hline \multicolumn{9}{|c|}{$\begin{array}{l}\text { Cond: Conductivity; Turb: Turbidity; D.O.: Dissolved Oxygen; COD: Chemical Oxygen Demand; TSS } \\
\text { Total Suspended Solids; TDS, Total Dissolved Solids; VSS: Volatile Suspended Solids; VDS: Volatile } \\
\text { Dissolved Solids. } \\
{ }^{\#} \text { TU: Toxicity Units }=100 / \mathrm{EC}_{50} . \quad+{ }^{+} \text {: singular points (isolated maximum) not included in the averages. }\end{array}$} \\
\hline
\end{tabular}

About the Microtox, it is important to observe that the two sites located in the lagoon (number of order 1 and 2 or R1 and R2) do not reveal toxicity $(<1$ TU) in all the periods, independently that the COD, in particular, was between 170 and $250 \mathrm{mg} / \mathrm{L}$ in these sites. The no-detection of toxicity, the over saturation of oxygen in the waters by moment (up to $8 \mathrm{mg} / \mathrm{L}$ ), due to the presence of algae, and the existence of fish in some parts to the lagoon, leads to the conclusion that this water body has a much better quality than the HCLR. 

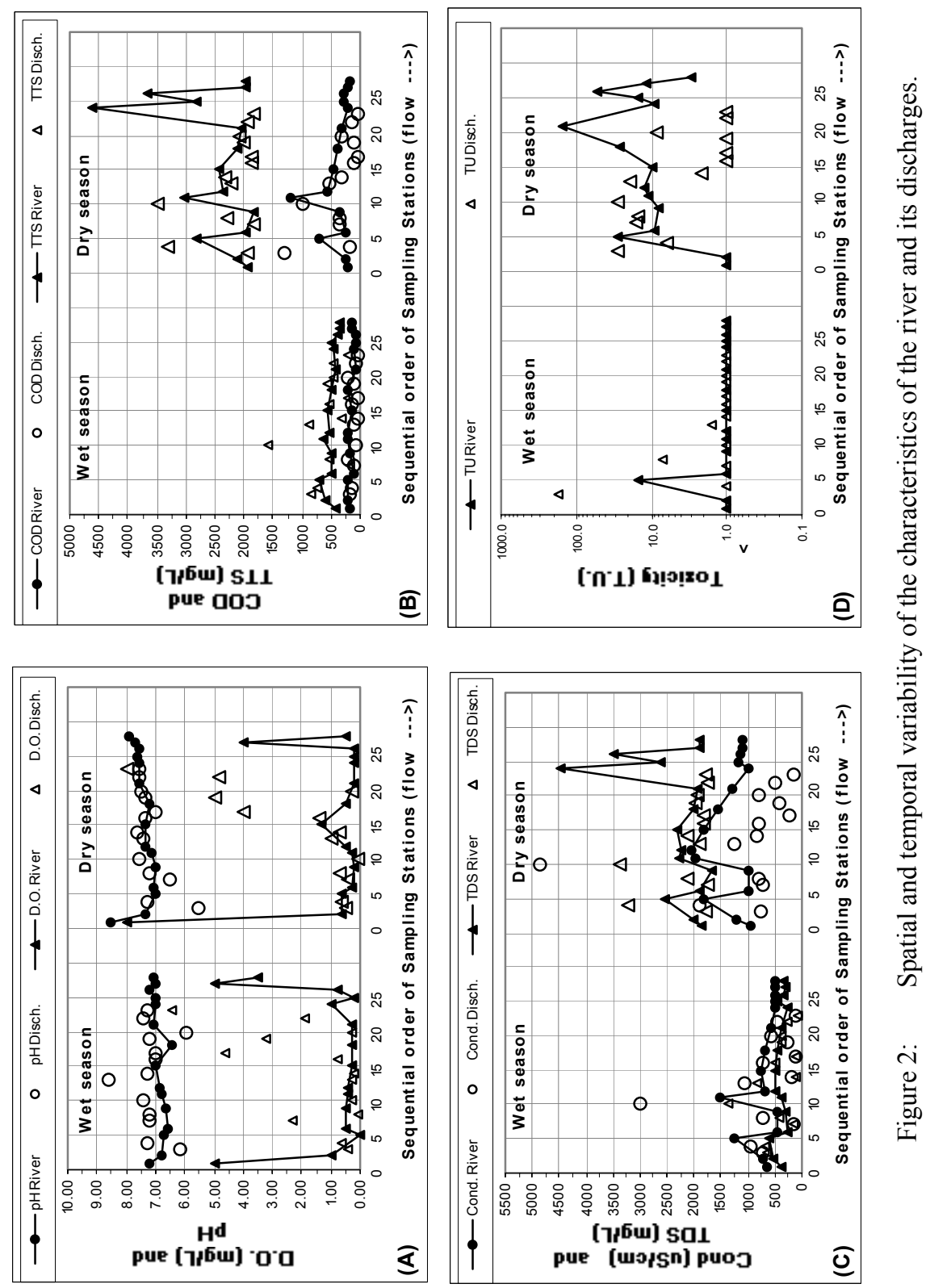
The contrast between the relatively high COD values and the innocuousness to the Microtox test organism, suggests that the form of the COD components present in the lagoon should be evaluated in future researches.

During the wet season, water is not toxic $(<1 \mathrm{TU})$ in almost all the sampling stations of the river water column, except for the third point (R4, 15 TU), apparently affected (just locally) by the first important discharge (D1) that has an exceptionally high toxicity of 170 TU. For the dry season campaign, the trend is the opposite: except in the two sites of the lagoon (as discussed previously), all the samples were showing some toxic characteristics (3 to $150 \mathrm{TU})$. The maximum of $150 \mathrm{TU}$ detected locally in the R11 station is not explicable only by the monitored discharges.

When using the Microtox, currently, intervals of $<1 \mathrm{TU}$ are considered as "non-toxic", 1.01 to 1.70 as "slightly to moderately toxic", from 1.8 to 2.6 as "toxic to very toxic" and > 5.3 TU as "extremely toxic" (Bennett and Cuttage [9]). In the present research, for comparison, the waters from a local municipal wastewater treatment plant were evaluated, finding a toxicity of 9.24 TU in the influent and $<1 \mathrm{TU}$ in the effluent (hormesis). The latter shows that due to its high sensibility, the no-detection of toxicity in the lagoon and other sites means the guarantee of non-distress, whereas the medium values around 9 TU may only mean the presence of more or less loaded normal municipal wastewaters.

To evaluate the vocation of the river water use for irrigation, one should refer to the Mexican Agreement CE-CCA-001/89 that stipulates the Ecologic Criteria used to classify water bodies in the country (DOF [10]). Among the numerous parameters considered for non-restricted irrigation, are the $\mathrm{pH}$ (4.5 to 9), conductivity $(<1000 \mu \mathrm{S} / \mathrm{cm})$, total dissolved solids (TDS $<500 \mathrm{mg} / \mathrm{L}$ ) and the total suspended solids (TSS $<50 \mathrm{mg} / \mathrm{L}$ ). The $\mathrm{pH}$ around 7 was always agreed. In half of the river stations during the wet season, and in all of them during the dry season, the TSS limits were exceeded. The frequency of exceeding the limits for the other parameters are 13 and $73 \%$ for conductivity and 20 and $100 \%$ for the TDS, respectively for the wet and dry periods. So the HCLR does not comply with the requirements for non-restricted irrigation.

\subsection{Discharges characteristics and their impacts}

The standards that regulate the discharges in the Lerma River are established in the Mexican Norm, NOM 001 (DOF [11]). For the vocation of use in irrigation that the course has, the accepted limits are: $\mathrm{T} \max$ of $40^{\circ} \mathrm{C}, \mathrm{pH}$ of between 5 and 10 , and average monthly concentrations smaller to $150 \mathrm{mg} / \mathrm{L}$ of TSS and $150 \mathrm{mg} / \mathrm{L}$ of $\mathrm{BOD}_{5}$, among other parameters.

The information about the discharges characteristics is summarized in Table 1 and Figure 2. The maximum temperature detected in the discharges was of $32^{\circ} \mathrm{C}$ for the D5 station (effluent from a treatment plant of an industrial park), but there was not any exceeding of the Norm. A low $\mathrm{pH}$ (5.5) was detected in the discharge from Tenango (D1, zone with much leather treatment activities). There was not any exceeding of the $\mathrm{pH}$ limits, but the minimum value of 5.5 detected in D1 constitutes a first alert about the nature of this discharge. 
In high waters, there was an exceeding in the limits for the TSS in 5 of the 13 evaluated discharges (D1, D5 and rivers D7, D10 and D12, with 162 to 200 $\mathrm{mg} / \mathrm{L}$ TSS). In low waters, the rivers D1 and D12 are still above their limits $(210$ and $167 \mathrm{mg} / \mathrm{L}$ ) and two more discharges are added (D4 and D6 with 316 and 210 $\mathrm{mg} / \mathrm{L}$ ). Suspended solids, in the case of the tributary rivers D7, D10 and D12, are the result of an erosion (inorganic matter), rather than pollution.

In dry season, the total solids, in the river waters, as well as in the discharges were particularly high (1800 top 4600, with an average of $2380 \mathrm{mg} / \mathrm{L}$ ), situation imputable to the dissolved fraction. In the wet season, the dilution substantially lessens the total solids concentrations (180 to 900, with an average of 500 and an extreme value of $1850 \mathrm{mg} / \mathrm{L}$ in discharge D5).

About the oxygen demand, the standards for discharges are stipulated in $\mathrm{BOD}_{5}(150 \mathrm{mg} / \mathrm{L}$ as monthly average), while the measurements in this research were done in COD. A gross comparison can be made by using typical $\mathrm{BOD}_{5} / \mathrm{COD}$ ratios for municipal wastewaters. In the most favorable scenario (ratio $\mathrm{BOD}_{5} / \mathrm{COD}$ of 0.4 ; Metcalf and Eddy, 1991), the average $\mathrm{BOD}_{5}$ of the discharges would be in $45 \mathrm{mg} / \mathrm{L}$ during the wet season (ranging from 15 to 90 $\mathrm{mg} / \mathrm{L}$ ), against $146 \mathrm{mg} / \mathrm{L} \mathrm{BOD}_{5}$ in the dry season ( 8 to $252 \mathrm{mg} / \mathrm{L}$ range). With a conservative approach, not any discharge would exceed the $150 \mathrm{mg} / \mathrm{L} \mathrm{BOD}_{5}$ limit during the rainy period, whereas in low waters, the D1 discharge (Tenango, $525 \mathrm{mg} / \mathrm{L}$ ), D5 (industrial plant effluent, $400 \mathrm{mg} / \mathrm{L}$ ) and D6 (Toteltepec Stream, where the effluent from a municipal plant joins, $212 \mathrm{mg} / \mathrm{L}$ ) would exceed the limits.

The parameters of COD, dissolved oxygen, conductivity, dissolved solids and toxicity are not included in the current regulation of the discharges. However, they allow appreciating even better the conditions of the discharges and their impact. Generally, in Figure 2, except for the $\mathrm{O}_{2}$, always that a discharge has shown a relatively high value of a parameter, there was an evident response in the river (peaks denoting a local impact of some discharges). The $\mathrm{O}_{2}$ high levels of the tributary rivers do not succeed elevating the low $\mathrm{O}_{2}$ levels in the HCLR. The two first COD and TSS peaks, that are perceptible in the dry season data (Figure 2B), are imputable to D1 and D5 (1300 and $1000 \mathrm{mg} / \mathrm{L}$ COD). The highest conductivity (Figure 2C) still takes place in D5 (4800 and $3000 \mu \mathrm{S} / \mathrm{cm}$ depending on the period). In the wet season, the first of the only 3 discharges that show toxicity is, precisely, the D1 (170 TU) with a noticeable impact in R3. The other two discharges with a toxic nature were D5 with 7 TU and mildly D6, with 1.5 TU. On the contrary, in the dry season, almost all the discharges (except D8 and 4 of the 6 tributary rivers evaluated) revealed a toxic nature (between 2 and 29 TU). The maximum were registered in D1 and D5.

Among the evaluated flows, the D1 and D5 discharges outstand as the ones of higher impact, however, in dry season, out of the 4 tributary rivers and the canal of one of the municipal plants (D8), all the large discharges contribute to the deterioration of river Lerma.

Generally, the tributary rivers are in a much better condition compared to the Lerma. They act as diluents of the waters and contribute to maintain the flow rate in the HCLR. 


\subsection{Similitude between the average characteristics of the river and its discharge}

The information presented in Table 1 gives evidence of a great similitude between the average characteristics of the waters, in the rivers versus the discharges, in the same season (dry season or wet season). It can be observed, for example, that the average conductivities are of 1344 (river) and $1079 \mu \mathrm{S} / \mathrm{cm}$ (discharge) in wet season against 684 and $698 \mu \mathrm{S} / \mathrm{cm}$ in dry season, for the river and discharge waters respectively. Other illustrative pairs are $(161,136)$ and $(61$, 68) NTU for turbidity, $(388,364)$ and $(149,112) \mathrm{mg} / \mathrm{L}$ for the COD, $(164,124)$ $(92,115) \mathrm{mg} / \mathrm{L}$ of TSS. The data pairs relative to the volatile organic matter (VSS and VDS) also show a similar composition average.

\section{Conclusions}

Along the 60 kilometers of the High Course of Lerma River, 51 discharges with a diameter or width that vary from 0.3 to $15 \mathrm{~m}$ were identified. Based on the inventory of the discharges, a monitoring network of 21 stations in the river and 13 in the important discharges $(>2 \mathrm{~m})$ was proposed.

The application of the network to monitor the discharges and the Lerma waters quality showed a great similitude between the average characteristics of the inflows and the river itself, in both the wet and dry season.

In the two evaluated periods, oxygen was found exhausted $(<0.5 \mathrm{mg} / \mathrm{L})$ almost all along the river, with COD and TDS average levels of 390 and 2350 $\mathrm{mg} / \mathrm{L}$ in dry season, against 150 and $400 \mathrm{mg} / \mathrm{L}$ in wet season. In the wet season, the river water, in general is not toxic $(T U<1)$ whereas that in dry season, excluding the lagoon, all the stations revealed some toxicity in the Microtox system (2.9 to 150 , with an average of $27 \mathrm{TU})$.

Among the evaluated discharges, two outstood as the ones with the most important impact (D1 and D5). However, in the dry season, out from 4 tributaries and the effluent of one of the municipal plants, all the large discharges contribute to the deterioration of the River Lerma.

Four of the six small evaluated tributaries, as well as the lagoon, are in relative good conditions ( 2 to $8 \mathrm{mg} / \mathrm{L}$ D.O., TU $<1$ ), acting as diluents and renewal of the HCLR flow rate.

In summary, the results obtained evidenced the actual state of the river during the dry season, quite a main wastewater collector, showing the urgency to implement a sanitation program in the basin and initiate remediation of the watercourse.

\section{Acknowledgements}

The authors wish to acknowledge the grant \# CONACYT 37909T by the Mexican National Commission of Science and Technology. Thanks also to the Autonomous University of the State of Mexico, sponsor of this paper. 


\section{References}

[1] CCRECRL, In spanish "Atlas Ecológico de la Cuenca Hidrográfica del Río Lerma", Tome I, ed. Talleres Gráficos y de Cultura, "Comisión Coordinadora para la Recuperación Ecológica de la Cuenca Alta del Río Lerma", Toluca, Mexico, 414 p., 1993.

[2] De la Fuente J.L., Hernández G. \& Marín L.E., Heavy metal concentration in the sediments of the upper Lerma Basin, Mexico. Aquatic Ecosystems of Mexico, ed. Bachuys Publisher, Leiden, the Netherlands, pp. 15-27, 2000.

[3] Avila-Pérez, P., Garcia-Aragón, J.A., Díaz-Delgado, C., Tejeda-Vega, S. \& Reyes-Gutiérrez, R. Heavy metal distribution in bottom sediments of a Mexican reservoir. Aquatic Ecosystem Health \& Management, 5(2), pp. 205-216, 2002.

[4] Barceló, Q. I. D., Solís, C. H. E., González, C. C., Avila, P. P. \& García, J.A. Determination of Cadmium and Lead Species in the Water Column of the Jose Antonio Alzate Reservoir, Mexico. Water Environment Research, 72(2), pp. 132-140, 2000.

[5] Mantilla-Morales, G., Izurieta-Davíla, J., Sanvicente-Sánchez, H., In spanish "Identificación de zonas de contaminación del río lerma", Avances en Hidráulica 6, ed. Aparicio F.J., Cuarnavaca, Mexico, pp. 347$352,2000$.

[6] APHA, Standards Methods, $17^{\text {th }}$ ed. APHA-AWWA-WPCF, Washington D. C., USA, 1989.

[7] Hinojosa-Peña, A., In Spanish "Diseño de una red estratégica de monitoreo para el curso alto del río Lerma", M.Sc. dissertation, Autonomous University of The State of Mexico, Toluca, Mexico, 2006.

[8] Ramírez, B. A. \& Hernández, L., In spanish "Diseño e implementación de una base de datos para el curso alto del río Lerma., B. Sc. dissertation, Autonomous University of The State of Mexico, Toluca, Mexico, 2004.

[9] Bennett, J. \& Cuttage, J., Review and evaluation of Microtox test for freshwater sediments, Report of the Washington State Department of Ecology, Olympia, Washington, USA, 1992.

[10] DOF, In Spanish "Norma CE-CCA-001/89: criterios ecológicos de calidad del agua". Diario Oficial de la Federación, Dic., 2, 1989.

[11] DOF, In Spanish "NOM-001-ECOL-1996", Diario Oficial de la Federación, Jan, 6, 1997. 